\title{
Oncology
}

Arii, S. 21

Ariizumi, S. 21

Arizumi, T. 51, 82

Azuma, M. 3

Chen, I-S. 64

Chen, M.-S. 40

Cheng, J.C.-H. 64

Fujimoto, K. 3, 13

Fujinaga, Y. 21

Fukuda, K. 44

Graber, M. 64

Hagiwara, S. 51, 82

Harada, K.H. 75, 88

Hatanaka, K. 51

Hayashi, N. 3

Hsu, F.-M. 64

Ichikawa, T. 21

Ida, H. 82

Igura, T. 44

Ikai, I. 75, 88

Imai, Y. 21, 44
Inoue, T. 51, 82

Ishida, T. 3

Izumi, N. 21

Jiang, W. 69

Kato, M. 3, 13

Kawada, N. 13

Kim, D.Y. 34

Kim, T. 21

Kim, Y.H. 34

Kitai, S. 51, 82

Kitao, A. 21

Kobayashi, S. 21

Kogita, S. 44

Koong, A.C. 64

Kudo, M. 1, 3, 13, 21, 51, 58, 75, 82, 88, 93

Makino, Y. 44

Matsui, O. 21

Minami, Y. 51, 58, 82

Minata, M. 75, 88

Morikawa, H. 13

Murakami, T. 44
Nagai, T. 82

Nishida, N. 51, 75, 82, 88, 93

Ohama, H. 44

Ohashi, H. 44

Peng, Z.-W. 40

Sakamoto, M. 21

Sakurai, T. 51, 82

Sawai, Y. 44

Shiina, T. 3

Takamura, M. 44

Takayasu, K. 28

Takehara, T. 3

Takita, M. 51, 82

Tsai, C.-L. 64

Ueshima, K. 3, 51, 82

Yada, N. 3, 13, 51, 82

Yamada, Y. 3

Yamamoto, K. 3

Yamasaki, M. 3

Zeng, Z.-C 69

\section{Subject Index Vol. 84, Suppl. 1, 2013}

BCLC staging system 28

Biomarker 64

Chronic hepatitis 3

Computed tomography 58

Contrast-enhanced ultrasonography 51

Defect-reperfusion imaging 51

DNA methylation 82

E-cadherin 75,88

EOB-MRI 21

Epigenetics 82

Exome analysis 93

Expert consensus 21

FibroScan 13

Genome-wide association study 93

Guidelines 69
Hepatocellular carcinoma 21, 28, 34, 40, $44,51,58,64,69,75,82,88,93$

Japanese guidelines 28

Liver fibrosis 3,13

- stiffness 13

Magnetic resonance imaging 58

Metastasis 88

Molecular diagnosis 82

Multimodality fusion imaging 44

Proximity ligation assay 64

Radiation therapy 69

Radiofrequency ablation 40, 44, 51

Radiotherapy 64

Real-time tissue elastography 3,13

Recurrence 75, 88
Transarterial chemoembolization 34

Transcatheter arterial chemoembolization $28,40,58$

Treatment algorithm 28

- response 51

Tumor suppressor gene 82

Ultrasonography 58

- fusion imaging 44

Ultrasound elastography 3

Vascular endothelial growth factor 75, 88

Volume navigation system 44

Whole-genome sequencing 93

Yttrium-90 34 